\title{
A Critical Race Inquiry of African American Female Law Students' Educational Experiences at a Racially Diverse Law School
}

\author{
Chloe Lancaster \\ The University of South Florida \\ Yonghong Xu \\ The University of Memphis \\ U.S.A. \\ Elin Ovrebo \\ The University of Memphis \\ U.S.A. \\ Eric Hosman \\ The University of Memphis \\ U.S.A.
}

\begin{abstract}
The purpose of this research is to examine how African American female law students' educational experiences have been impacted by institutionalized racism. Using Critical Race Theory, we analyzed data from a focus group comprised of five, $3^{\text {rd }}$-year black female law students attending a racially diverse campus in the Mid-South. Results indicate that systemic racism and sexism affects all aspects of law school experience for black females. Nonetheless, the strong presence of an institutional honor council, mentors, and minority professors served as protective factors to assist participants navigate a racist and patriarchal legal system.
\end{abstract}

An increase in women and minorities occupying positions in the higher echelons of the legal profession suggests the field of law is fairly represented by race and gender. However, $88 \%$ of lawyers are white, and according to Bureau of Labor Statistics, Law is the least racially diverse among the prestige professions (Rhode, 2015). As noted by Garces (2012), this a disappointing trend given that lawyers populate some of the most powerful offices. In higher education, women are better represented and constitute nearly 50\% of the average law student population (Calleros, 2006). Nonetheless, the diversity pipeline terminates at the institutional level, as women are five times less likely to make partner in a law firm and are underrepresented at the managerial partner level (Olivas, 2005).

For minorities, the field of law is fraught with barriers. While minorities groups constitute one-third of the US population and nearly $20 \%$ of the Law school population, they make up fewer than $7 \%$ of law firm partners, and only $9 \%$ of legal counsels working in large corporations (Rhode, 2015). In one analysis of the student body at a law school in the Midwest, researchers found that minorities comprised $7 \%$ of the student body, but less than $1 \%$ of regionally practicing lawyers (Wu \& Schumacher, 2014). Given these statistics, and the historical replication of white males securing lucrative positions in the legal field, it is reasonable to assert that systemic barriers associated with racism, privilege, and social capital continue to exert a dominant influence on the composition of the legal profession.

Researchers have described the racial homogeneity of the law profession as a "Diversity Crisis," believed to result from explicit and implicit bias ubiquitous to the professional pipeline (Negowetti, 2015). First, entrance to law school rests almost exclusively on applicants LSAT scores, despite the recognition that standardized assessments are not an effective screening tool for students of diversity, nor predictive of their later success in the legal profession (Olivas, 2005; Reynoso \& Amron, 2002). Second, the practice of affirmative action in law school admissions leads to the stereotype that minority students have inferior academic achievement. Such perceptions negatively impact their academic and social development (Payne-Pikus et al., 2010), and foreground the exclusion of minority law students from formal and formal networking opportunities, deemed essential for one's legal career development (Rhode, 2015). Third: Stereotypes that minority lawyers as less competent persist into the workplace. One study revealed that lawyers were likely to denigrate legal memo's if they believed the author was a minority (Negowetti, 2015). Finally, researchers suggest that female lawyers are caught up in a double bind. Feminine traits are associated with weakness, submission, 
and are considered antithetical to qualities of an effective lawyer, yet, women who present as too assertive are admonished for being too aggressive (Reynosa \& Amron, 2002; Pratt, 2012).

Furthermore, within the legal field, family release time is equated to "slacking," stigmatizing female lawyers who need to take maternity leave or work part-time to bring up a family (Rhode, 2015). The net effect of institutionalized racism, ethnocentricity, and sexism is to promulgate white men as the bastions of the legal profession and white male norms as the signature of rightness.

\section{African Americans women and the law}

Black females are one of the fastest growing populations on college campuses earning nearly $2 / 3$ of all degrees conferred by African Americans each year (Evenson \& Pratt, 2012; JBHE Foundation, 2001; Rhode, 2015). Although law schools were historically the terrain of white men, and later black men, black women, since the passage of the civil rights legislation the number of women obtaining law degrees has been steadily increasing (JBHE Foundation, 2001). Law school enrollment reports indicate a similar trend. One recent report suggests that black women constitute nearly $60 \%$ of the African American population at the nations 50 highest ranked law schools (Wu \& Schumacher, 2014). Similar patterns have been found across HBCU law schools with women representing 58\% of total enrolment (Brown $\&$ Davis, 2001). The ascent of women in higher education, inclusive of the legal field, has been attributed to a variety of factors indicative of cultural norms and systemic oppression that more adversely affect black men. Within the black community, college attendance and academic ambition are sometimes equated with acting white, and men have been found to internalize this negative association to a greater degree than women. (JBHE, Foundation, 2001) Academically black women appear to have the advantage, often performing better on standardized assessments that measure writing ability (Pratt, 2012). Internalized oppression has been found higher among black men than women, resultant in a "victim mentality', which interferes with self-efficacy and goal setting (Garces, 2012). Finally, law firms get employment credit by hiring double minorities, referred to as "two-fers", placing black female law graduates in high demand (Rhode, 2015).

\section{Purpose of Study}

Although law continues as a male-dominated profession, black women appear to be outpacing their black male counterparts in gaining access. Unfortunately, the upward mobility of educated black females is not reflected in the demographic make-up of the legal field as women, particularly minority women, are grossly under-represented (Rhode, 2015). While the white male advantage is well documented at the professional level, less is known about exclusionary practices that may oppress minority females at the institutional level. The purpose of this study is to examine black female students' experiences of institutional, professional, and cultural bias, within a racially diverse law school in the mid-south. Given the noted differences in the diversity pipeline, the intent in conducting this study was to shed light on how systemic prejudice differentially affects black female law students. Our study was guided by the research question: How does diversity impact the experiences of African American females attending law school in the midsouth region?

\section{Critical Race Theory}

We used critical race theory (CRT) to examine how black law students' educational experiences have been impacted by factors of race and gender. Critical Race Theory is a theoretical framework that critically examines the imbalanced distribution of resources and power by race, class, gender, and minority groups within society (Hylton, 2012). In contrast to other apolitical theories, CRT recognizes that groups devoid of power and wealth will inevitably encounter adversity resultant from their systemic marginalization and oppression. Given substantial knowledge of the pervasive bias in the legal system, indicative of broader social stratification, CRT is an appropriate method to help shed light on how institutionalized racism affects the experience of black female students' experiences in law school.

\section{Method \\ Participants}

We employed a typical case sampling procedure (Patton, 2005) to identify 5 African American $3^{\text {rd }}$-year law students attending a racially diverse institution in the mid-south of the United States. The school is considered small $(\mathrm{n}=325)$, comprised of $55 \%$ males and $45 \%$ females, and a $25 \%$ minority student population. The participants were recruited via emails from the school's diversity office with an added incentive to receive a $\$ 50$ gift card upon participation in a focus group. Those students who expressed an interest were forwarded an email from the second author to establish a time and date to conduct the focus group. Our 5 participants were between the age 25-28 and came from rural and urban areas across the south and mid-south. All had attended public school, and while 3 out of the 5 were traditional first generation, 2 of the participants' parents had earned advanced degrees as adults. This study was conducted as part of a 
funded project examining the experiences of diversity of all non-majority law students within the same institution. Give the richness, breadth, and depth of the data we decided to pursue this prong of the research as an independent inquiry.

\section{Researchers}

Our research team comprised of three tenured female professors in counselor education (first author), educational research (second author), and counseling psychology, and a doctoral student in educational research (fourth author). The first author is a Caucasian British national with a specialization in conducting qualitative research with nonmajority groups. The second author is a Chinese national who specializes in survey research to examine the social and institutional factors that promote persistence among marginalized populations. The third author is a Norwegian national with a specialization in qualitative research and cross-cultural adjustment issues. The fourth author is a Caucasian American male with experience conducting survey research and working with large data sets.

\section{Data Collection}

All participants were initially interviewed in a focus group that lasted 3 hours. Following the initial interview, participants were contacted a second time to comment on the accuracy and relevance of emerging themes, and on one final occasion to provide feedback on the stability and applicability of final themes. Given the sensitive nature of the topic, we decided a focus group would be more conducive for an honest exploration and examination of shared and diverging experiences. Although the research team was composed of three internationals, as non-black researchers we were aware that participants may be more comfortable sharing in the presence of African American peers. We developed a 10 item, semi-structured, protocol to examine participants experiences as a student of diversity attending law school. The protocol consisted of questions related to students' institutional, academic, and professional interactions and how they were impacted by race and gender.

\section{Data Analysis}

We used grounded theory procedures to collect, organize and analyze the data. Grounded theory provides a stage approach for data analysis consisting of categorization, mapping, focused stage, and theory building (Charmaz, 2011; Glasser \& Strauss, 1967; Shkedi, 2005; Strauss \& Corbin, 1990). Because, this research was exploratory in nature, we followed Shkedi's adapted grounded theory method, which omits the theory building stage from the data analysis process. Following data collection, all interviews were transcribed verbatim by the fourth author and verified for accuracy by the first author. The preponderance of data analysis was conducted by the first and third author. In the first stage of data analysis, we established our "in vivo" categories by making line by line notes in the margins of the transcripts that surmised or captured the point being conveyed. We were aware to keep our language close to the words of the participants, to ensure we avoided forcing the data into pre-conceived categories. Although the initial categories were eventually re-named and worked into more conceptual themes, we kept an original copy of the categories intact. This served as an important source of triangulation during the later stages of data analysis as we were able to compare increasingly abstract interpretations back to our initial reflections.

In the second, mapping, stage, we began to organize the data in terms of fundamental similarities and common patterns. While the categorization process had yielded an array of potentially compatible, yet discrete, fragments of data during the mapping process, we began to organize each fragment into an orderly configuration. Through the process of mapping, we assembled data into vertical 'identification' categories that captured dominant ideas and then horizontal categories, which provided substantive supporting ideas. In the final, focused stage, of data of analysis, we developed overarching core themes, around which the main and sub-themes appeared to orbit. We also referred to CRT to guide the organization and conceptualization of themes.

\section{Triangulation}

Through the triangulation process, we examined the stability and prevalence of these categories. After the initial interview, we engaged in the process of member checking, wherein we contacted participants two more times to give input on our data analysis. As a second source of triangulation, we utilized a peer auditor, a colleague skilled in qualitative inquiry yet unfamiliar with the current study, to conduct an independent analysis of our raw data. Finally, we invited an expert informant, a black female lawyer, who had graduated from the same program to provide feedback on our overarching core categories. The high degree of convergence in the feedback provided by the participants, peer auditor, and expert informant, and the absence of new data, confirmed that we had reached data saturation, and acceptable confirmation of the stability of our core categories, which could now be depicted as our main themes. Table 1 represents the core and supporting themes derived during the focused stage. To ensure fidelity to the rich data that emerged from the focus group and follow up interviews, we intentionally positioned thick descriptors (Geertz, 1994), illustrative of each respective theme throughout the results section. 


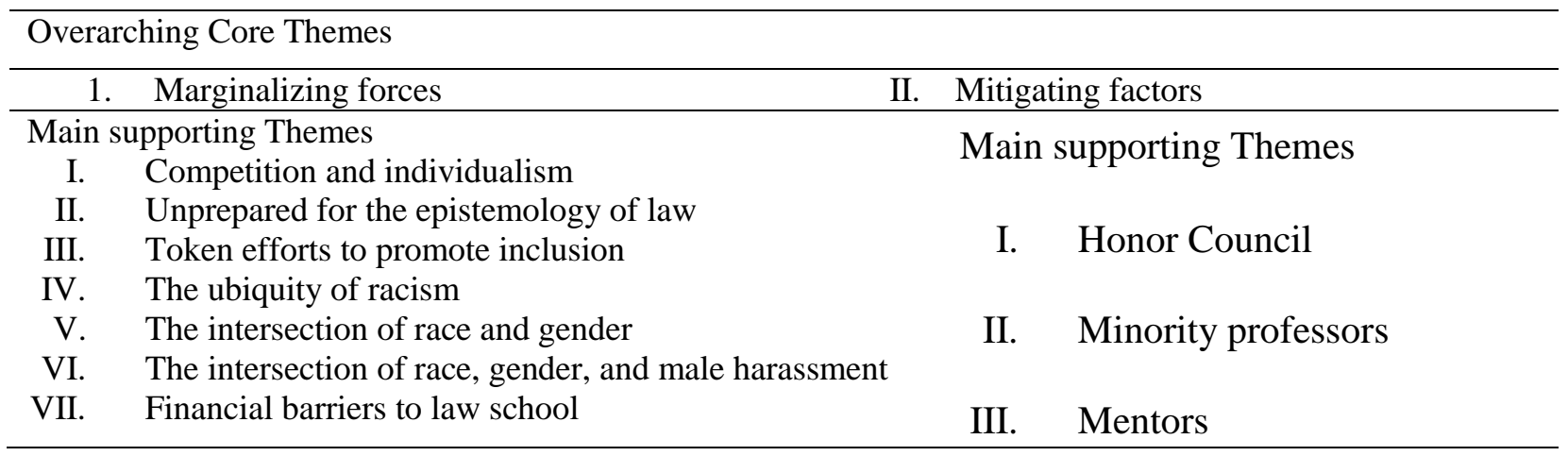

Table 1: Overarching core and main supporting themes

\section{Results}

The final themes are organized into two intersecting, yet dialectical dimensions: Marginalizing forces and mitigating factors. Marginalizing effects speak to elements in the institutional and professional environment that isolated the students and intensified the pressure of the law school experiences. By contrast, mitigating factors denote the presence of buffering forces that both protected and elevated them above the fray of systemic racism and a professional culture wherein sexual harassment proliferates.

\section{Marginalizing Forces}

Competition and individualism. This theme emerged from participants' descriptions of the academic and institutional environment that promoted self- preservation and weak student bonds. Achieving good grades was discussed as imperative to one's success as they were directly linked to access to career opportunities such as summer associates positions, considered imperative for securing employment post-graduation. The practice of grading on the curve was one that intensified pressure and placed students in competition with each other

I don't know if you guys know how our grading works, we are graded on a bell curve. It's a forced bell curve. So it's purposely to weed us out so, and I mean, and it's very subjective and arbitrary, so there's another way that they really trying to break you. To break you down, because when it comes down to it, if you're in a class of 60 people, Maybe six people are going to making A.

Because of the competition, students became focused on their own performance studying independently and avoiding group study. Support systems were sought outside the institution and included parents, spouses, church, and friends with no ties to law.

In law school, if you study together, someone takes you down a rabbit hole about the wrong thing, or they're focusing on some nuance of the law, you might get to the exam and realize that you studied the wrong parts, So, I think for a lot of people you get afraid to study with other people. I study with maybe one person, but it's not like studying together. It's more of we're in the same room and we're studying.

Ultimately the participants discussed the law school environment as deliberately intended to dehumanize students to prepare them to enter the very tough field of litigation. "It's very harsh. It's like this right of passage in law school, you have to almost kill yourself and want to kill yourself, and then you're really a lawyer."

Unprepared for the epistemology of law. This theme is conceptually related to A culture of competition and individualism, as it speaks to unexplored aspects of the academic environment that create implicit barriers for minority students, especially those from disadvantaged public schools. The participants mentioned entering law school, expecting to accrue a body of factual legal knowledge; however, this expectation was quickly undermined when they encountered an epistemological system starkly different from their previous education. Referring to her undergraduate psychology degree, participant 1 indicated:

There's a logic and a rhyme and a reason for things, it's like ok, we start here, and have a logical progression through the material. However, once you've learned the principals of reading case law, everything else is subjective, which is probably why my adjustment to law school was a little difficult sometimes, cause there's none of that here."

In this respect, the academic strategies, such as studying information for a test, did not transfer to law school.

There's like a million different points you can start to study and learn the information, 
This stuff is all over the place, and you can always argue either side. That's the thing with the exam; there is no right answer

Participants stated that they eventually adapted, yet noticed that local, predominately black, students struggled with this transition, as they were not prepared to engage the level of critical thinking and were reputed to frequently drop out by the second semester or just not return for L2 year.

I've noticed that some of the minority students can't keep up with the workload.

I've noticed that every year a large chunk of minority students don't come back. And it's not because they're less intelligent, but it's because, especially if they're from here, the way our social systems are set up, the way our educational system is set up, it's not set up to prepare everyone for this kind of academic environment.

Token efforts to promote inclusion. The school was ostensibly dedicated to attracting students of diversity, as reflected in the demographic characteristics of the institution. While this orientation may appear commendable, according to the participants the school's salient priority was bar-passage rates and this preoccupation eclipsed all other institutional efforts. "I think unfortunately with our class all the race issues are put on the back burner. They're (the school) concerned about our bar passage rate- it dropped to 70\%, and that's driving everything." Within this climate, institutional measures intended to support all student success did little to ameliorate the deep rivets of inequality.

For example, the school encouraged professors to utilize an "open door policy," to support the success of all students. The institution, however, misread the needs of minority females who were not inclined to establish informal relationships with instructors. "Faculty are open, warm, available. I'm not really interested in getting to know them on an informal level- It's transactional. I appreciate more of a business relationship with them." Conversely, the open-door policy provided an avenue for predominately white students to forge close relationships with their professors. One student mentioned that you'd hear professors ask their white male students about their family or engage in sportsthemed, small talk.

Pejorative remarks about the minorities receiving special treatment were common-place and made the participants cautious toward engaging their professors at an informal level, lest other students accused them of leveraging preferential treatment based on color. In this environment, professors who openly favored underrepresented student groups exacerbated misperceptions: "I had a professor last semester, who was white, but favored minority students- I hated it." By contrast, the participants indicated that they preferred professors who were "tough and fair." Referring to one of their professors, participant 3 indicated, "she's harsh, yes, but she's fair. She'll treat a white person like that, and she'll treat a black person like that. She doesn't see anything but the work product that you give her

Another institutional measure intended to promote the façade of equity was the presence of the diversity office. According to the participants the diversity office functioned as a spurious appendage to the law school and was not well integrated into everyday operations. While the diversity office was helpful and supportive, their impact on the school at a cultural level was negligible. For example, few students attended their events and professional development workshops. From the participants' perspective, the office's major shortcoming was it had not been effective in bringing conversations about race and gender to the foreground. Participants said that occasionally their professors would mention privilege, yet, these discussions were sporadic and not integrated into a school-wide strategy to promote diversity.

Moreover, the students stated that the school administration was culpable for disabling the power of the office:

We have a diversity office coordinator who is amazing. The thing is, you don't know what she does because the school doesn't back her. I mean, let's be honest, she's not supported. And she's very passionate and can do amazing things, but, she's just one person and if the administration isn't going to put the resources her way, what's she going to do?

The ubiquity of racism. Racism punctuated students' academic and professional environment, with student borne racism discussed as being most explicit. Many Caucasian students, particularly male and from affluent backgrounds, lacked both the experience and motivation to interact with students of diversity. Participants frequently discussed these students as devoid of empathy, especially in their disdain for all non-traditional groups (e.g., racial, gender, religious) "There are people who are just blatantly, intentionally hurtful and hateful to certain groups of people. And it shows." This group of students was even known for making racially and sexually derogative comments in the presence of their minority professors. One participant mentioned being, "tired of being the angry black women", and now defaulted to silence when in the presence of certain students in her class as, "every comment that comes out of their mouth is racist." Micro aggressions about affirmative action were rife, especially comments about minorities LSAT and bar scores and the assumption that all minorities, "get a free ride" In response to these assaults, the participants noticed that minority students tended to unite in defense of one another: 
I've noticed that minorities here are very ready and able and willing to speak out about other groups, not just our own, and I think it's because we all kind of understand that experience and that feeling of being treated differently; prejudice and oppression and racism. So, you know, I'm speaking out about Latino culture. I'm not Latina at all, but I'm very happy to, you know, join in.

The intersection of race and gender. As double minorities, issues of race were compounded by race-gendered disparities pronounced across multiple contexts inside and outside the institution. Within the institution, participants mentioned that classmates would make comments every time they changed their hair, "It's like they've never been around black women." During the focus group participant, 3 mentioned how she was treated differently compared to her black peers, "because I've got "good" hair and light skin, and I'm still half black." As a mixed-race female, she had to contend with other macro aggressions related to racial her heritage, "Oh, your hair is so pretty. Are you black?" These experiences shed light on the bias toward a Caucasian female look prevalent in the legal profession. Two participants noted that they must avoid wearing their hair natural in professional contexts.

My hair is natural, and I love my natural hair, but if I'm going on an interview, I have to go and get my hair done-But my hair is natural, so if it rains today, there goes my hair. It's curly now.

Resultant from this systemic bias the participants mentioned that the black female attorneys they meet all look the same, "Hair relaxed, straightened to fit more Caucasian look." However, even conformity to the Caucasian female ideal does not preclude incidences of racism

When I go into an interview in 15 minutes and I realize they don't like me, and it's not because of what I said out of my mouth, it's because of how I look. I have to consider, as a female, um, this dress, it goes down past my knee, and it's not clinging to my body or is it simply because I'm black

The intersection of race, gender, and sexual harassment. Sexual harassment, well documented in the legal profession was an oppressive force for the participants. As alluded to in the previous excerpt, participants had to avoid dressing in a manner that could be perceived as overly sexualized as this invited unwanted attention. At networking events, they would regularly get propositioned by fellow law students and practicing attorneys. Participant 2 suggested that she deliberately avoids networking events "Right now I have no power so I just avoid networking events where sexual harassment is pervasive" The tone of their responses indicated that many male lawyers felt entitled to behave in a sexually aggressive manner. Participant 1 mentioned that she regularly receives inappropriate propositions through her LinkedIn in account:

It's LinkedIn, this is not Facebook You know? And I told them I'm married, and they still persist. I'm a law student, right? There's no respect, it doesn't matter that this person may only have been a lawyer for the last year, so it not even that far ahead of me in the field. Sexual harassment is bad.

The participants encountered sexual harassment from other sources within the legal system. At the courthouse, participants mentioned that the bailiff and security guard would always make comments about their appearance.

I would say it's hard to even in the courtroom even not dealing with judges and attorneys. Because I deal with the security guard who doesn't even have enough education to have an intellectual conversation with me that thinks because I'm female that he can flirt with me. And then you go to a courtroom, be ready- there's a deputy in there and bailiff in there and they're gonna comment on the shoes I wore, the dress I wore, how cute I look today. And ask me for my phone number for the tenth time, but meanwhile, I've got a domestic violence client that I'm trying to calm down.

To contend with these assailants, one participant mentioned that as minority females they have learned to be strong, "My mom, growing up, said you're gonna have to be a little less sensitive than that, cupcake." As stated by participant 2:

My Dad really is my best friend, and he raised me to be very strong and very tough. He's got four daughters [laughs] and three granddaughters. And we were raised strong. Taught me how to give a firm handshake. Taught me how to negotiate my salary and my pay and made sure that I knew my stuff.

While being tough promoted self-preservation, the participants mentioned that they were caught in a double bind, as masking one's sexuality and acting too forthright could come at a professional cost. "You don't want too dowdy because you've got to be appealing, eye-catching, as some judges and attorneys won't hire you. And when you talk too much like a man in the legal field and you're not respected." In response, to this paradox, participants discussed developing mannerisms and a cadence that conveyed femininity yet asserted their rights

I had to learn how to tell you no in a pleasant way. I've learned how to negotiate with men (in the legal field) in a way that doesn't make them think that I'm flirting with them- but I'm smiling so I don't come off like I'm being too masculine 
Financial barriers to law school. In brief, the financial burden of attending law school weighed heavily upon the participants. "My consistent barrier is money. It's always money- it stinks because you're already stressed with the school work, and when you have a financial barrier too, that just makes it even worse." Although the students were in the $3^{\text {rd }}$ year and had traversed the financial hurdle that precludes many, particularly first-generation-minority students, from entering higher education the school's requirement to attend school full-time and not work created tremendous pressure. "It's especially hard in law school because during my undergraduate I worked a full-time job. I always had money, and if I didn't have enough money, I'd work more hours, or get a better job that pays more." For our participants seeking financial support from their families was not an option. As highlighted by participant 4 asking her mom for help would, "take away from my brother and sister." Despite securing scholarships, taking out loans, and secretly working part-time work, the cost of law school was unremitting:

You can take out loans, which I have, but you can only take our up to your cost of, like, attendance, and the cost of attendance doesn't accurately reflect that I bought a brand-new car before I decided to go to law school, so now I have a car note that I'm responsible and you can't borrow for that.

Perhaps a more insidious aspect of the financial barrier was a lack of funds precluded them from participating in the professional event and could interfere with future employment opportunities:

We have to compete and I'm thinking about the academic setting, but I have to compete with other students financially too- because they may have the money to go to Atlanta and participate in a networking event, and I can't take off work or afford to go.

In addition to the cost of travel participants drew attention to the expense of professional attire, "clothes, people don't think about clothes. Suits are expensive, and when you're my height and my size, you have to get everything especially tailored." Participants also reflected that the uneven distribution of wealth among law student perpetuates a sociological system that favors white males.

$80 \%$ of all attorneys are white men. A good chunk of the future lawyers to come out of here are the children of lawyers, So they already have like opportunities set up for them. We're already competing in the job market where quite a few of the jobs are taken because somebody knows somebody. And they can afford to spend the summer doing an unpaid externship- There's a luxury to that. I have to work.

\section{Mitigating Factors}

Honor Council. The participants all articulated an attitude of resiliency toward racial and sexist attitudes and behaviors encountered in law school. They also drew attention to those institutional practices that successfully promoted inclusion for non-majority students. First, the Honor Council, a body of students and faculty responsible for monitoring unethical behavior was a strong presence on campus. This council helped to prevent incidences of dishonest practices noted to occur at other law schools (e.g., hiding books, giving wrong answers in a study group, blocking off study rooms)

They take the Honor Council and the honor code very, very serious here. Um, and it doesn't matter how great you are, how likable you are, it doesn't even matter who your dad is. I've known people who have gotten reprimanded by the Honor Council that have very influential parents. That's' one aspect this school doesn't waver, and so it's very helpful.

Minority professors. Although few in number, black law professors were highly regarded by the participants. The students did not mention having a special bond or receive mentorship from these faculty. Rather, minority faculty stood out as role models and provided validation to the presence of the black student population. Moreover, the students mentioned they had achieved better grades because they simply felt more comfortable in their classes.

I found that my best, my best grades have come from both of my minority, double minority professors. My black female professors, I get the best grades in their course. And not because, I'm black, there are no names, they're giving the grade to 98721 . But I'm engaged, I know that I can ask them a question from a cultural standpoint

The participants' desire for fair treatment also transferred to their interactions with minority faculty, which were noted to be formal, and attenuated by concern that the appearance of favoritism could invite criticism from other students.

You know, my first class was with a minority professor. She was black, and she was a female, and she was known for putting people out of class. The woman called on me every day- it never failed. And every day I was like, did I say the right thing? Because there was no validation until the class was over, and then I went to her office to talk and she was like "You did good." But while we were in that classroom, she was going to push me and never give me special attention 
Mentors. Mentors in the legal field were instrumental in strengthening participants' resiliency, through serving as role models, aiding them in the establishment of career goals, and furnishing them with the tools to navigate barriers. One striking characteristic of this theme was the emergence of pipe-line mentoring. Although the school formally matched all law school students with a mentor in the school and community, all participants discussed the presence of multiple mentors in their life, since their school-days, who had guided and pushed them to pursue their career goals. Most interesting was the participants' identification of several current mentors who they had met through school-based matches, legal organizations, externships, and moot court. Participant 4, met one of her mentors during a summer externship with the CDC.

I love her because she is this gorgeous, beautiful black woman who is also a JD/MPH and she is a team leader at CDCAnd she's kept in touch with me. For our evaluation at the end of my externship, she said "You can do whatever you want to do, just choose and decide now what you want, and we're going to make a list of all the things you want. I want you to look up job announcements. I'm going to make sure that by the end of the year you've fulfilled every one of those requirements for those job announcements so that you have the qualifications necessary to do what you want to do."

Although participant 4 described this individual as her "warm and fuzzy mentor" the participants equally appreciated mentors who were benevolent yet tough. Referring to her mentor she met on moot court participant one mentioned:

She's my mentor more than I wanted her to be. We don't have warm, fuzzy feelings about each other by any means. We work well together and I work for her. I'm on her travel team. she has been a mentor as far as she has honed my writing skills and fostered my assertiveness more than anybody else

While black mentors were treasured, non-black minority mentors were invaluable, "I like having her, though, because I feel like she kind of understands things because she's kind of a minority. She's a woman and she's also gay. So I think it's like, you know what I mean? Like she kind of understands the nuances of, like, being treated differently." Also valued were their white mentors who understood diversity:

I also have to say some of my best mentors, since I've been here, have actually been non-minorities that understood the complexities of being a minority. Because, quite frankly, they have the connections that I don't have, they know things that a lot of minority mentors wouldn't be able to tell me, and they know how to protect me in a different way. So they know that, while this minority might think that this person is great, they know as a non-minority that, behind closed doors, that person is awful. And so they know to tell me. Stay away, or don't trust this individual.

\section{Discussion}

The assertion that the profession of law is beset with a diversity crisis prompted us to utilize critical race theory as a conceptual lens to frame this study and analyze the data. Participant narratives confirmed that stratification by race and gender continue to oppress minorities entering the legal field and ensures the perpetuation of a white, predominately male, hierarchy. Our results indicate that oppression operates at multiple levels. Within the educational milieu, mechanisms are in place that creates implicit barriers for students of diversity. The finding that a competitive and individualistic culture demarcates the learning environment could create obstacles for African Americans who according to the broader research are more inclined toward field-dependent learning, with emphasis cooperation and group recognition (Bonner, 2000). Added to this barrier is the epistemological base that could be prohibitive for students whose educational experiences have not prepared them to engage complex reasoning and critical thinking skills. Once again this could be detrimental to poor African American students, subject to an educational system where resources and quality programs are divided along racial and economic lines.

With the ascent of an African American lawyer to the highest office of government and presence of African American females in prestigious institutions of the US judiciary, projects a message that race no longer an issue within the legal field, and promulgates a climate supportive of color-blind attitudes. Racism and its corollary white privilege are ubiquitous forces for our participants, echoing what is referred to within CRT literature as "transparency," or the notion that white people have the luxury of not having to consider race in the context of their everyday interactions (Evenson \& Pratt, 2012). Our findings extend this concept by highlighting the blatant disregard and scorn toward diversity, articulated by students identified as belonging to the privileged white class. Our findings also shed light on explicit bias against affirmative action, expressed through unfiltered comments about diverse law students weakening the prestige of the institution. These results provide anecdotal evidence that race-conscious affirmative action, while vital for the diversification of the legal pipeline, may contribute to on-going institutional and professional prejudice (Evenson \& Pratt, 2012). 
Institutional measures intended to create conduits for achieving parity did little to relieve the participants' sense of isolation and constant awareness of their positionality within a biased system. The presence of a diversity office within a law school represents a notable accomplishment for expanding the rights of minorities within the law school, yet the silo of the office from everyday operations precluded it from impacting the broader law-school culture. In response to the academic intensity of law school, the institution encouraged professors to operate open door policy. Most interesting was the participants' preference for formal relationships and their reluctance to appear too familiar with professors. This echoes other research that indicates black students may appreciate transactional oriented studentfaculty relations (Lancaster \& Xu, in press; Meeuwisse, Severiens, \& Born, 2010). Participants' alertness toward their status as double minorities and their associated maneuvering of the racial landscape stands in contrast to the white transparency. This was evident in the white students' enthusiasm for forging friendly relations with professors, free of concern toward the appearance of favoritism. By contrast, our participants preferred fair-minded professors who rated students by the quality of their work. In a similar respect, the honor council alleviated pressure as it forced transparency and non-discriminatory practices. CRT contends that the uneven distribution of financial resources in society provided a mechanism for the white elite to replicate their power and privilege across each successive generation. The legal field is in many respects symbolic of this process. Indeed, within this study the law school, albeit diverse, was replete with affluent white students from generational legal families.

While affirmative action policy has provided a structural and financial bridge for minorities to penetrate the legal field, a lack of financial resources continues to threaten students' ascent into the field. For example, although our participants relied on their families for psychological support, they could not turn to them financially. Sadly, a lack of money disadvantaged the students in a highly competitive environment by precluding their participation in networking events and compelling them to seek employment which interfered with their studies. Our findings indicate a need for financial resources to be allocated to support all aspects of participation in law school that goes beyond the disbursement of funds for tuition, books, and rudimentary living expenses.

The theme, intersection of race and gender, highlights how our participants, as double minorities were discriminated against in ways that do not neatly fit into categories of racism or sexism. This finding aligns to critical race feminist theory that illuminates how the intellectual separation of racism and sexism is a silencing force for minority women, insofar as racism studies focus on minorities, and sexism studies on female status, yet, neither give voice to the minority female groups who experience both forms of oppression (Crenshaw, 1989). Within the current study, the lamentable absence of discussions of diversity within a racially diverse law school implicates the institution in practices that promote the promulgation of white male hierarchy. Given the results, it seems reasonable to conjecture that until the intersectionality of race and gender is addressed as part a coordinated institutional effort to become more inclusive, minority females will continue to suffer the dual effects of racism and patriarchy. The corollary finding that race and gender also intersects with incidences of sexual harassment reinforces the critical race feminist thesis that historical stereotypes subjugate black women and reinforce white male power (Smith, 2013). It has been noted that black female lawyers must rebuff both the "angry black female" and the "hypersexual Jezebel" stereotypes by tempering their emotional reactions and deemphasizing their femininity (Pratt, 2012). Our study revealed that these stereotypes continue to fuel attitudes and behavior, including sexual harassment, and are acutely manifest at the law school level. Once again it appears that diversity efforts should shed light on this systemic problem and provide a safe environment for establishing a dialogue about conflicting messages transmitted to black female law students.

The students in our study were entering a profession that devalued both women and minorities, yet as illuminated by our results our participants were not victims of an unfair system, rather they deftly navigated the racial and gender traps and were able to articulate their identity incongruence with their sense of self. This was illuminated in their rejection of a homogenous Caucasian look, and cultivation of interpersonal skills that asserted their rights, and projected professionalism in the face of racial and sexual impropriety. This finding refutes the suggestion that ambitious African American's must conform to the norms of mainstream white culture to achieve social and occupational parity (FriesBritt, 2000). Our participants buffered themselves through a cadre of self-preserving strategies and bonded with other minority students to strengthen their community and shield themselves and one another from racial assaults. Once again this aligns with other studies that found high achieving black women preserve their racial identity by actively resisting surrendering to white culture and value systems (Evenson \& Pratt, 2012).

Mentors and black instructors were an invaluable source of psycho-social, academic, and career support. The students identified multiple mentors both in the present and at earlier stages of their educational careers, providing evidentiary support for the development of a strategic mentoring program that bridges the gap between high school and college. Within the field of law, lawyers who have been mentored are more likely to make partner and experience greater occupational satisfaction (Laband\& Lentz, 1999). Once again, our participants were proactive agents of their success narrative, actively procuring mentorship and attributing value to the role of mentors in their journey. 
Moreover, students' relationship with their mentors were complex and challenged traditional depictions of mentormentee dyads (DuBois \& Karcher, 2014). Participants recognized that not all mentors have to be, "warm and fuzzy," and valued relationships that at times could be difficult, understanding these relationships were a catalyst for learning and professional advancement. Our findings also illuminate how white mentors, who understand diversity issues, serve as ally's, further buffering minority women by providing insider information. In addition to pipeline mentoring, our findings highlight the positive effect of diverse faculty upon the psyche and educational attainment of minority students and underline the importance of recruiting and retaining faculty of diversity as a mechanism to moderate the diversity crisis in the legal field.

\section{Conclusion}

This study shed light on African American females' experiences of diversity within a racially diverse law school. Although the school was located in a racially diverse region and actively recruited students of diversity, forces of racism and patriarchy mediated all aspects of their professional induction experiences. The presence of a diversity office within the institution represents a commendable effort, yet until the office is structurally embedded into school functioning, students such as the ones in this study will continue to experience an oppressive educational and professional environment.

One suggestion that emerged from this study is the need for an open dialogue that begins early in the legal pipeline. Making transparent the experiences of minority women could potentially heighten awareness among non-minority students toward their plight and decrease tolerance toward incidences of gendered-racism. Salient to our findings were mechanisms that promote positive scholastic and professional outcomes and our participants' resiliency in navigating hostile terrain with poise and a strong sense of racial identity.

\section{Limitations}

The themes derived from the research were based on African American females' experiences of diversity within a single racially diverse institution in the Mid-South. Despite achieving thematic saturation in the data analysis, this limitation restricts transferability of results to other populations of African American law students attending the same or similar institutions. The study is most notably limited by an absence of participants who had already dropped out of law school. To the extent that our participants had transcended the multiple educational, financial, and cultural barriers to law school, their narrative may mask the impact of racism, sexism, and sexual harassment upon students who prematurely departed the institution. Furthermore, our study is sorely limited by the number of participants. While their honest and analytical accounts of gendered racism provided exceptionally rich data, this study would have been enhanced by the inclusion of more participants.

\section{References}

Bonner, F. A. (2000). African American giftedness: Our nation's deferred dream. Journal of Black Studies, 30(5), 643663.

Brown, M. C., \& Davis, J. E. (2001). The historically Black college as social contract, social capital, and social equalizer. Peabody Journal of Education, 76(1), 31-49.

Calleros, C. R. (2006). Patching leaks in the diversity pipeline to law school and the bar. California Western Law Review, 43, 131-150.

Charmaz, K. (2011). Grounded theory methods in social justice research. The Sage handbook of qualitative research, 4 , 359-380.

Chused, R. H. (1988). The hiring and retention of minorities and women on American law school faculties. University of Pennsylvania Law Review, 137(2), 537-569.

Crenshaw, K. (1989). Demarginalizing the intersection of race and sex: A black feminist critique of antidiscrimination doctrine, feminist theory, and antiracist politics. University of Chicago Legal Forum, 1, 139-167

DuBois, D. L. \&Karcher, M. J. (2014). Handbook of Youth Mentoring. Thousand Oaks, CA: Sage Publications.

Evensen, D. H., \& Pratt, C. D. (2012). The end of the pipeline: a journey of recognition for African Americans entering the legal profession. Durham, North Carolina: Carolina Academic Press.

Fries-Britt, S. (2000). Identity Development of High-Ability Black Collegians. New directions for teaching and learning, 82, 55-65.

Garces, L. M. (2012). Racial Diversity, Legitimacy, and the Citizenry: The Impact of Affirmative Action Bans on Graduate School Enrollment. The Review of Higher Education, 36(1), 93-132. 
Geertz, C. (1994). Thick description: Toward an interpretive theory of culture. Readings in the philosophy of social science, 213-231.

Glaser, B. G., \& Strauss, A. L. (1967). The discovery of grounded theory: strategies for qualitative theory. Chicago, Il: Aldine Publishing Co

Hylton, K. (2012). Talk the talk, walk the walk: defining Critical Race Theory in research. Race Ethnicity and Education, 15(1), 23-41.

Laband, D. N., \& Lentz, B. F. (1999). The impact of having a mentor on earnings and promotion: evidence from a panel study of lawyers. Applied Economics Letters, 6(12), 785-787.

Lancaster, C. \& Xu, Y. (in press). Challenges and supports for African American STEM student persistence: A case study at a racially diverse four-year institution. Journal of Negro Education.

Meeuwisse, M., Severiens, S. E., \& Born, M. (2010). Learning environment, interaction, sense of belonging, and study success in ethnically diverse student groups. Research in Higher Education, 51, 6, 528-545.

Negowetti, N. (2015). Implicit bias and the legal profession's' diversity crisis': A call for self-reflection.

Olivas, M. A. (2005). Law school admissions after Grutter: Student bodies, pipeline theory, and the river. Journal of Legal Education, 55(1/2), 16-27.

Orfield, G. (2001). Diversity challenged: Evidence on the impact of affirmative action. Cambridge, MA: Harvard Education Publishing Group.

Patton, M. Q. (2005). Qualitative research. John Wiley \& Sons, Ltd.

Payne-Pikus, M. R., Hagan, J., \& Nelson, R. L. (2010). Experiencing discrimination: race and retention in America's largest law firms. Law \& Society Review, 44(3-4), 553-584.

Pratt, C. D. (2012). Sisters in law: Black women lawyers' struggle for advancement. Michigan State Law Review, 2012, $1777-1779$.

Reynoso, C., \&Amron, C. (2002). Diversity in legal education: A broader view, a deeper commitment. Journal of Legal Education, 52, 491-496.

Rhode, D. L. (2015). The trouble with lawyers. Oxford University Press, USA.

Shkedi, A. (2005). Multiple case narrative: A qualitative approach to studying multiple populations. Philadelphia, PA: John Benjamins Publishing.

Smith, S. (2013). Black feminism and intersectionality. International Socialist Review, 91, 6-24.

Strauss, A., \& Corbin, J. (1990). Basics of qualitative research (Vol. 15). Newbury Park, CA: Sage.

The JBHE Foundation (2001). Black women now dominate African-American law school enrollments. The Journal of Blacks in Higher Education, 30, 64-66.

Wu, N., \& Schumacher, S. C. (2014). Raising the Bar: Increasing and Sustaining Diversity within the Hennepin County Legal Community. 